\title{
Finite element model for unsteady open channel flows with sudden contraction/expansion
}

\author{
Abdul Latif Qureshi ${ }^{1}$, Ali Asghar Mahessar ${ }^{2}$ and Ahsanullah Baloch ${ }^{3}$ \\ ${ }^{I}$ Professor, Institute of Water Resources Engineering and Management, Mehran University Engineering \& \\ Technology, Jamshoro, Pakistan, \\ ${ }^{2}$ Ph. D Scholar, Institute of Water Resources Engineering and Management, Mehran University Engineering \\ and Technology, Jamshoro, Pakistan, \\ ${ }^{3}$ Professor, Department of Computer Science, Isra University, Hyderabad, Pakistan,
}

\begin{abstract}
Two-dimensional Finite Element model has been developed for computing incompressible fluid flow using Navier-Stokes equations applying Taylor-Galerkin technique. This approach allows exploring complex hydrodynamic phenomena to compute and analyze unsteady flow patterns in open channel with contraction and expansion. In this paper, numerical results were initially compared with analytical solution to validate the developed model, which reveal good qualitative and quantitative agreement with predictions of other numerical model. Numerical computations were made before, during and after contraction/expansion in two-dimensional channels, in order to understand the transient behavior due to increased length in the downstream. Streamline flow pattern and velocity distribution were computed for various Reynolds number (Re) values at different time units. It was found that wake on downstream side of contraction channel is increased with the increase in Reynolds number value. The present model yields realistic results for addressing irregular problems in the actual field situations, generally observed in open channels.
\end{abstract}

Keywords: Contraction/expansion, Finite element method, Streamline pattern, Unsteady, Velocity profiles

\section{Introduction}

The major investigation for computing unsteady flows in open channels has been carried out by physical modeling and field observations. The laboratory experiments and analytical solutions were also derived for some problems. However, analytical solutions can be derived for only limited class of problems. These include those that can be approximately with linear models and those that have simple geometry. While the highly non-linear nature of the governing of partial differential equations, makes it impossible to find the analytical solutions except in a handful of special cases. The complexity of problem led to the development of numerical methods for solving real problems [1]. The predictions are quite realistic when the model is applied to simulate some hypothetical cases such as flow patterns in channels/ natural rivers [2]. The numerical simulation of an unsteady flow in a contraction and expansion channel is most interest in the field of hydraulics engineering. These flows attracted to various investigators for determining the flow behavior especially at downstream of hydraulic structures. The contraction and expansion flow serve an ideal flow which contain the region of re-circulating and streamline flow [3]. Two-dimensional models give a better realistic description of the flow than that of one-dimensional model but less complicated than that of three-dimensional model [4]. Due to its simple scheme, the finite difference method (FDM) has widely been applied by investigators [5, 6 and 7]. However, rectangular mesh layout in FDM cannot fit for complex boundary conditions. In order to get high computational precision, the scale of rectangular meshes must be reduced, so that the time-step must be cut down. As a result, the efficiency of the model becomes low.

In contrast to finite difference techniques, the finite element method divides the solution domain into simply shape regions or "elements". Hence, the finite element method provides an alternative that is better suited for such systems [3].

Reference [8] has developed a mathematical model which was tested in a canal with sudden expansion; result shows that the flow rate, flow lines and vortex formed on both sides are asymmetric. The behavior of the flow, which has attracted experimental and theoretical study, appears to depend from the equations upon only one parameter i.e. the Reynolds Number (Re). The flow is steady when the values of Reynolds number are small. On the other hand, when values of Reynolds number are large, the flow becomes unsteady and the vortices are shed. As Reynolds number increases the vortices diminish in regularity and the effects of turbulence become increasingly more prominent [9]. For different Reynolds number $(\mathrm{Re})$ values, the pressure and velocity values have been computed using the parallel algorithm. It has been observed that the wake on the downstream side of square obstacle is increased with increase of Reynolds number [10]. Recently, flow through axisymmetric non-uniform rigid channel with varying degree of constriction in a forward and backward were discussed [11] numerically over a large range of Reynolds numbers (i.e. 100, 250 and 400). 
Reference [12] has introduced a Taylor-Galerkin/pressure-correction technique which was presented by [13] and [14] for Non-Newtonian flows. This scheme has been validated in two- dimensions, for unsteady flows [15]. The results of [16] studies suggested that semi-implicit form of Taylor Galerkin scheme with second order pressure-correction methodology for the Navier Stokes equations along with sediment transport equations is the robust in the case of validating with analytical solutions, laboratory observations and applying for simulating for sediment transport in alluvial channels. These changes have been utilized to develop a finite element Taylor Galerkin model for solving hydrodynamic problems accordingly.

\section{Governing Equations}

Governing Navier-Stokes equations are employed for developing a two-dimensional model for unsteady flow derived from conservation of mass and momentum equations consisted of velocity and pressure formulation of the incompressible fluid, which are described as under:

Continuity Equation

$$
\frac{\partial u}{\partial x}+\frac{\partial v}{\partial y}=0
$$

Momentum Equation

$$
\begin{aligned}
& \frac{\partial \mathrm{u}}{\partial \mathrm{t}}=v\left(\frac{\partial^{2} \mathrm{u}}{\partial \mathrm{x}^{2}}+\frac{\partial^{2} \mathrm{u}}{\partial \mathrm{y}^{2}}\right)-\mathrm{u} \frac{\partial \mathrm{u}}{\partial \mathrm{x}}-\mathrm{v} \frac{\partial \mathrm{u}}{\partial \mathrm{y}}-\frac{1}{\rho} \frac{\partial \mathrm{p}}{\partial \mathrm{x}} \\
& \frac{\partial \mathrm{v}}{\partial \mathrm{t}}=v\left(\frac{\partial^{2} \mathrm{v}}{\partial \mathrm{x}^{2}}+\frac{\partial^{2} \mathrm{v}}{\partial \mathrm{y}^{2}}\right)-\mathrm{u} \frac{\partial \mathrm{v}}{\partial \mathrm{x}}-\mathrm{v} \frac{\partial \mathrm{v}}{\partial \mathrm{y}}-\frac{1}{\rho} \frac{\partial \mathrm{p}}{\partial \mathrm{x}}
\end{aligned}
$$

Where $\mathrm{u}(\mathrm{x}, \mathrm{t})$ and $\mathrm{v}(\mathrm{y}, \mathrm{t})$ are the local velocity in longitudinal $(\mathrm{x})$ and vertical (y) directions respectively, $\mathrm{p}(\mathrm{x}, \mathrm{t})$ is the isotropic pressure (per unit density), $\mathrm{t}$ is time, $v$ is the kinematic viscosity $(\mu / \rho), \mu$ is dynamic fluid viscosity and $\rho$ is fluid density.

The governing system of equations was put into a non-dimensional form for better resolution. Nondimensional variables $\left(x^{*}, t^{*}, u^{*}\right.$ and $\left.p^{*}\right)$ by selecting a suitable characteristic scale as: $x=L x^{*}, t=(L / U) t^{*}, u$ $=\mathrm{Uu}^{*}, \mathrm{p}=\rho \mathrm{U}^{2} \mathrm{p}^{*}$.

Inserting non-dimensional values and discarding asterisks for brevity and simplicity. $U$ and $L$ are the characteristic velocity (inlet velocity) and length (size of the cross-section of channel), respectively. The above equations (1-3) may be rewritten in compact form as:

$\nabla . \mathbf{u}=0$

$\frac{\partial \mathbf{u}}{\partial \mathrm{t}}=\frac{1}{\mathrm{R}_{\mathrm{e}}} \nabla^{2} \mathbf{u}-\mathbf{u} \cdot \nabla \mathbf{u}-\nabla \mathbf{p}$

Where additionally $\mathrm{R}_{\mathrm{e}}=\frac{\rho \mathrm{UL}}{v}$ is Reynolds number,

\section{Development of Numerical Model}

For development of a model, finite element method has been used adopting two-step predictor Corrector technique and enhancing stability and accuracy, semi-implicit scheme has been suggested [17, 18]. For above governing system of equations (4 and 5), fully-discrete system in weak formulations has been implemented to develop 2-D numerical model. This model have 4 fractional steps for solutions of $\mathrm{u}^{1+1 / 2}, \mathrm{u}^{*}$, $\mathrm{u}^{\mathrm{n}+1}, \mathrm{p}^{\mathrm{n}+1}$, using given values of $\mathrm{u}^{*}$ and $\mathrm{p}^{*}$.

Step 1: Predict velocity $U$ at half time step $(n+1 / 2)$ level using following equation

$\left(\frac{2 \mathrm{M}}{\Delta \mathrm{t}}+\frac{\mathrm{S}_{\mathrm{u}}}{2 \mathrm{R}_{\mathrm{e}}}\right)\left(\mathrm{U}_{\mathrm{j}}^{\mathrm{n}+\frac{1}{2}}-\mathrm{U}_{\mathrm{j}}^{\mathrm{n}}\right)=\left[\frac{-\mathrm{S}_{\mathrm{u}}}{\mathrm{R}_{\mathrm{e}}} \mathrm{U}_{\mathrm{j}}-\mathrm{N}(\mathrm{U}) \mathrm{U}_{\mathrm{j}}+\mathrm{PL}_{\mathrm{k}}+\mathrm{b} . \mathrm{t}\right]^{\mathrm{n}}$

Step 2: Exercise the above information, compute $U^{*}$ and applying the following formulation

$\left(\frac{\mathrm{M}}{\Delta \mathrm{t}}+\frac{\mathrm{S}_{\mathrm{u}}}{2 \mathrm{R}_{\mathrm{e}}}\right)\left(\mathrm{U}_{\mathrm{j}}^{*}-\mathrm{U}_{\mathrm{j}}^{\mathrm{n}}\right)=\left[\frac{-\mathrm{S}_{\mathrm{u}}}{\mathrm{R}_{\mathrm{e}}} \mathrm{U}_{\mathrm{j}}+\mathrm{LP}_{\mathrm{k}}+\mathrm{b} \cdot \mathrm{t}\right]^{\mathrm{n}}-\mathrm{N}(\mathrm{U}) \mathrm{U}_{\mathrm{j}}^{\mathrm{n}+1 / 2}$ 
Step 3: Compute $P$ at full time ${ }^{(\mathrm{n}+1)}$ using velocity $U^{*}$ values

$$
\mathrm{K}\left(\mathrm{P}_{\mathrm{k}}^{\mathrm{n}+1}-\mathrm{P}_{\mathrm{k}}^{\mathrm{n}}\right)=\frac{-2}{\Delta \mathrm{t}} \mathbf{L U}_{\mathrm{j}}^{*}
$$

Step 4: Compute the second order $U$ at full time $(n+1)$ level and applying $U^{*}$ and $P^{n+1}$ values.

$$
\frac{2 \mathrm{M}}{\Delta \mathrm{t}}\left(\mathrm{U}_{\mathrm{j}}^{\mathrm{n}+1}-\mathrm{U}^{*}\right)=\mathrm{L}^{\mathrm{T}}\left(\mathrm{P}_{\mathrm{k}}^{\mathrm{n}+1}-\mathrm{P}_{\mathrm{k}}^{\mathrm{n}}\right)
$$

Where, $M, S_{u}, N(u), K, L, L^{T}$ are matrices and b. t. denotes boundary terms; for details refer [3].

\subsection{Validation of the model}

\section{Numerical Results and Discussions}

For validation of the developed model, a straight channel having width $B$ of $1 \mathrm{~m}$, and length $\mathrm{L}$ of $10 \mathrm{~m}$ has been selected. The fluid flow have viscosity $v$ of $10^{4} \mathrm{~m}^{2} / \mathrm{s}$, maximum velocity $U_{\mathrm{m}}$ of $0.5 \mathrm{~m} / \mathrm{s}$, discharge $\mathrm{Q}$ of $0.2667 \mathrm{~m}^{3} / \mathrm{s}$ and slope $S_{o}$ of 1 in 1000 . The details of problem description along with the analytical solution are available in [2]. The plan view of the channel is shown in Figure 1.

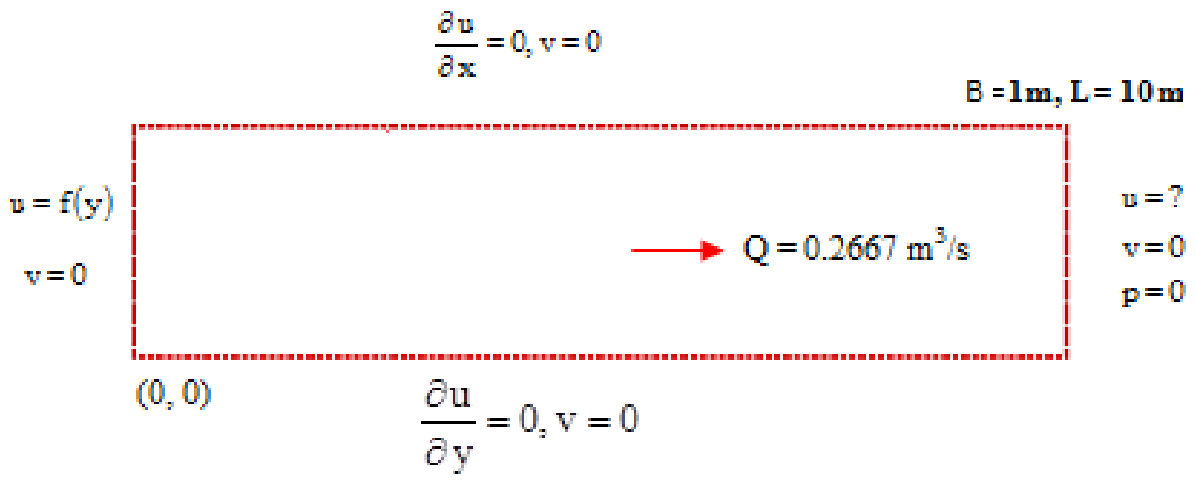

Fig. 1 Schematic diagram of channel

In this connection, a finite element mesh was developed using 2000 triangular element with 4221 total nodes and 9553 DOF (Degree of Freedom). The developed model has been used to compute velocities at various distances viz. $0.2,0.4,0.6,0.8$ and $1.0 \mathrm{~m}$, which are shown along with the analytical solution (calculated at $1.2 \mathrm{~m}$ from the inlet) in Figure 2. The solid curve in Figure 2 is the analytical solution and the velocity distributions show changes rapidly near the inlet and then gradually approaches to the desired analytical curve.

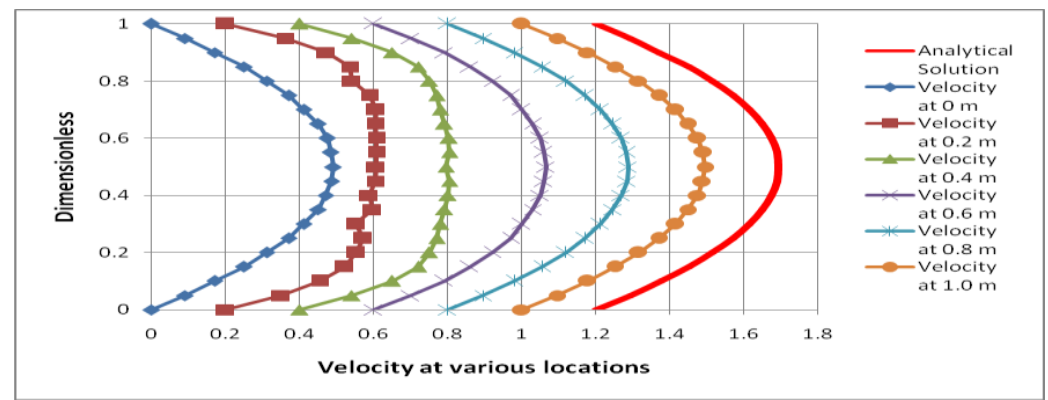

Fig. 2 Development of velocity profiles at various locations and the analytical solution

The developed model has been used to predict velocity values which are compared with available analytical solution and the numerical results of [2] (see Figure 3). The comparison reveals a good agreement among them which show the accuracy of the developed model. 


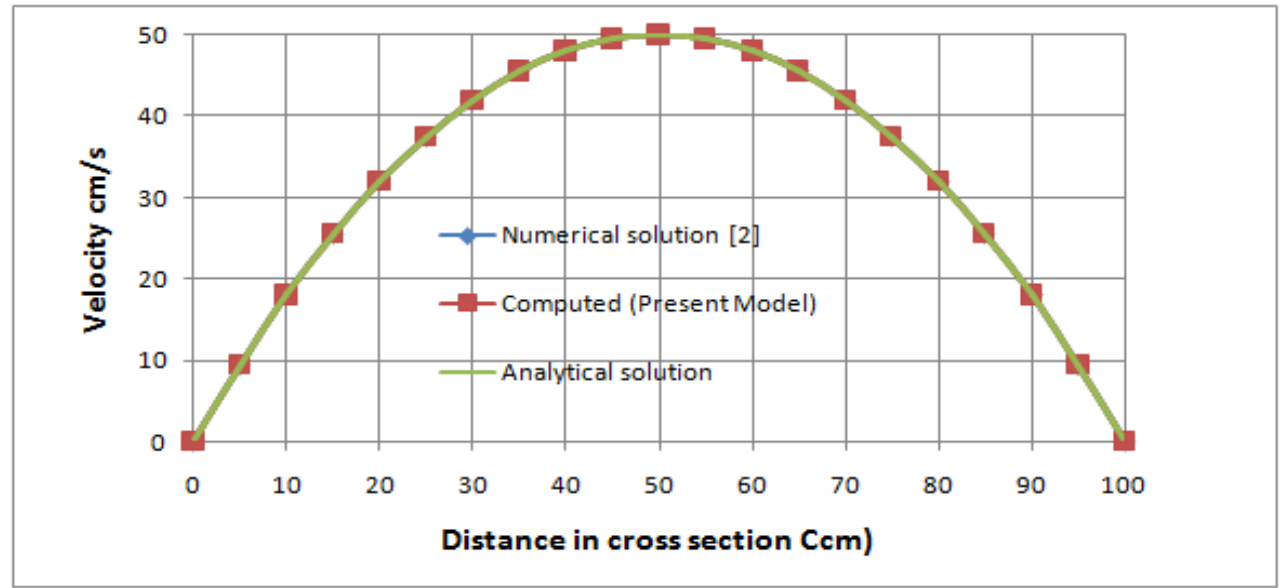

Fig. 3 Comparison of predicted FEM model results with analytical and numerical solutions

\subsection{Streamline pattern in channel with sudden contraction and expansion}

Two unsymmetrical channels of different lengths with contraction and expansion were selected to determine the flow behavior in terms of streamline pattern; schematic diagram of the channel is shown in Figure 4. Both channels have same width and contraction portion; however, upstream and downstream lengths are varying (see Table 1). In this table, detail of elements, vertex and velocity nodes are also described.

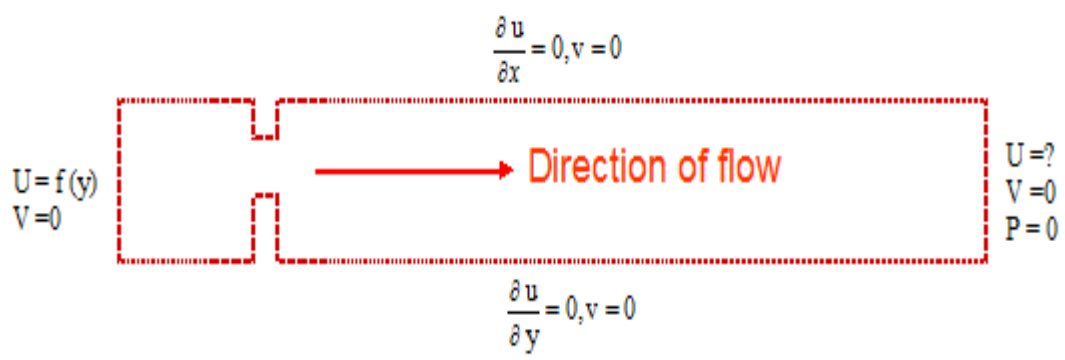

Fig. 4 Schematic diagram of a contraction/expansion 2-D channel

Table 1 Channel types, their dimensions and finite element meshes' description

\begin{tabular}{|c|c|c|c|c|c|c|c|c|c|}
\hline \multirow{2}{*}{$\begin{array}{c}\text { Type } \\
\text { of } \\
\text { Channel }\end{array}$} & \multirow{2}{*}{$\begin{array}{c}\text { Width } \\
(\mathrm{m})\end{array}$} & $\begin{array}{c}\text { Upstream } \\
\text { portion } \\
(\mathrm{m})\end{array}$ & $\begin{array}{c}\text { Contraction } \\
\text { portion } \\
(\mathrm{m})\end{array}$ & $\begin{array}{c}\text { Downstream } \\
\text { portion } \\
(\mathrm{m})\end{array}$ & $\begin{array}{c}\text { Total } \\
\text { Length } \\
(\mathrm{m})\end{array}$ & $\begin{array}{c}\text { Triangular } \\
\text { Elements }\end{array}$ & $\begin{array}{c}\text { Vertex } \\
\text { Nodes }\end{array}$ & $\begin{array}{c}\text { Velocity } \\
\text { Nodes }\end{array}$ & $\begin{array}{c}\text { Degrees } \\
\text { of } \\
\text { freedom }\end{array}$ \\
\hline $\begin{array}{c}\text { Short } \\
\text { Channel } \\
\text { (SC) }\end{array}$ & 50 & 30 & 10 & 60 & 100 & 9360 & 4863 & 19085 & 43033 \\
\hline $\begin{array}{c}\text { Long } \\
\text { Channel } \\
\text { (LC) }\end{array}$ & 50 & 55 & 10 & 290 & 355 & 19360 & 9963 & 39285 & 88533 \\
\hline
\end{tabular}

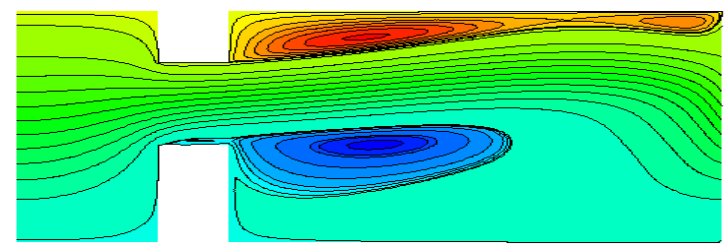

(a) Steady state behaviour observed in short channel at $\mathrm{Re}=10$ with $\mathrm{T}=783.8$ units

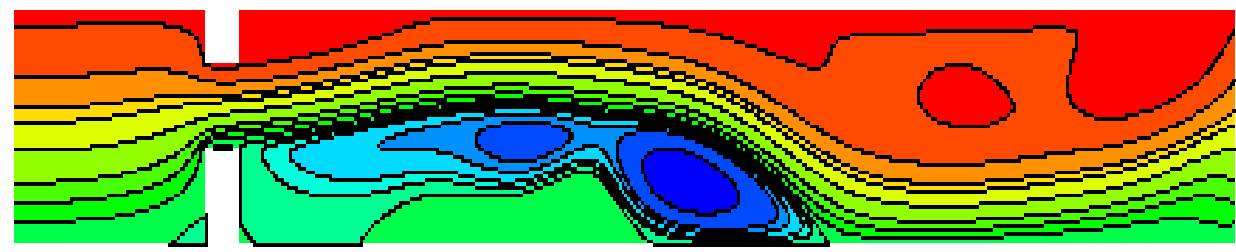

(b) Unsteady condition observed in long channel at $\mathrm{Re}=10$ with $\mathrm{T}=800$ units Fig. 5: Streamline pattern in short and long channels 
In addition to above, the long channel was used to predict unsteady state condition for increased Reynolds numbers viz. 25, 50, 100 and 500. Streamline patterns are presented in Figure 6 (a \& b) for Re values of 25 and 50 with 800 time units. It was found that with increased Reynolds number value at the same time, the computed vortices are diminishing as compared against the small Re value.

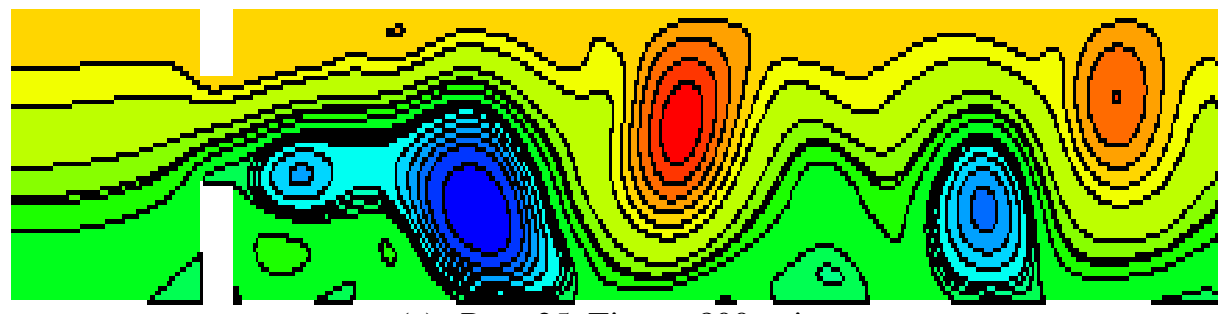

(a) $\mathrm{Re}=25$, Time $=800$ units

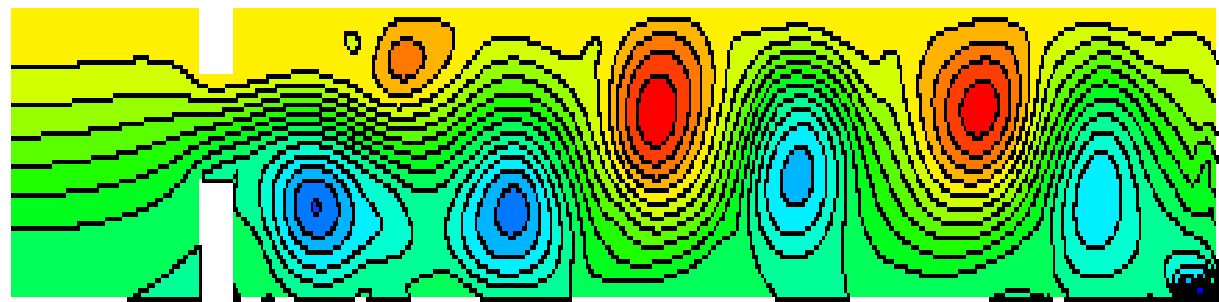

(b) $\operatorname{Re}=50$, Time $=800$ units

Fig. 6: Streamline pattern (Unsteady State Condition)

The simulations were continued for high Reynolds number values of 100, 200, 300 and more with various time units utilizing only long channel in order to have clear picture of streamline behavior at downstream. In this paper, streamline patterns for Re values of 100 and 500 at 400 time units are made using Tec-plot software (see Figure 7). The vortices grow very large and project some considerable distance of the expansion plane, and then the longitudinal structure of entire eddy appears to increase non-linearly with increasing Reynolds number.

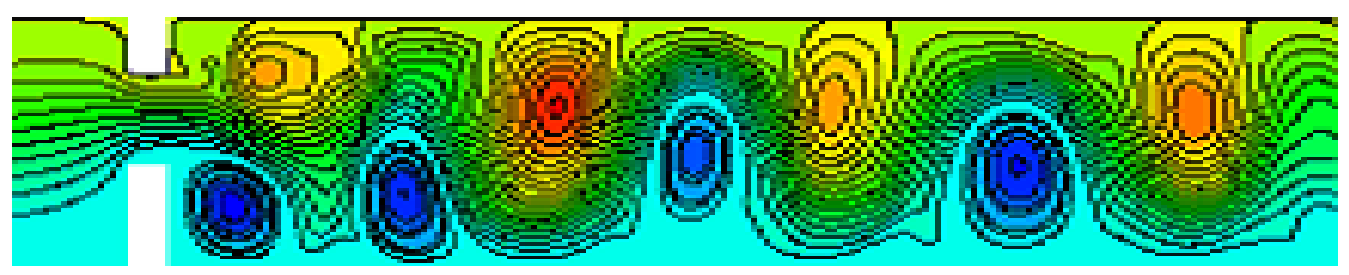

(a) $\operatorname{Re}=100 . \mathrm{T}=400$ units

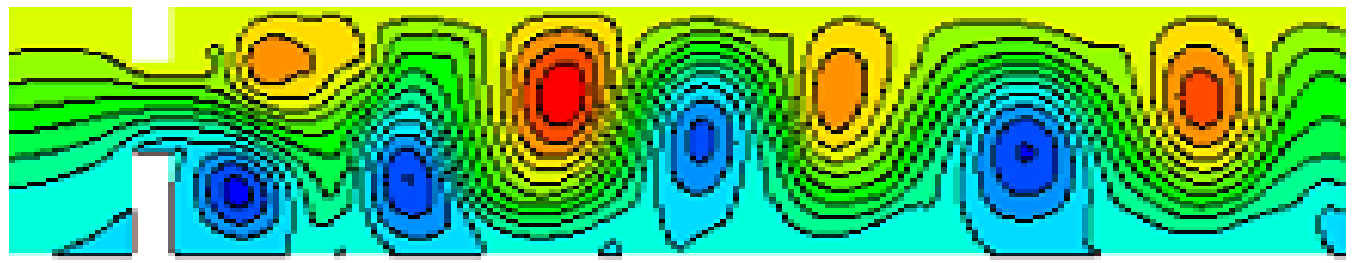

(b) $\operatorname{Re}=500, \mathrm{~T}=400$ units

Fig. 7 Streamline pattern $(\operatorname{Re}=100$ and 500)

\subsection{Velocity distribution at various locations}

A two-dimensional long channel (LC) with contraction/expansion having width $50 \mathrm{~m}$ and length $355 \mathrm{~m}$ have been selected to predict velocity distribution along channel width at various locations. In this connection, the dimensionless length of $\mathrm{X} / \mathrm{B}$ has been calculated and the channel is described in Figure 8 along with the velocity profile as inlet boundary condition as follows: 


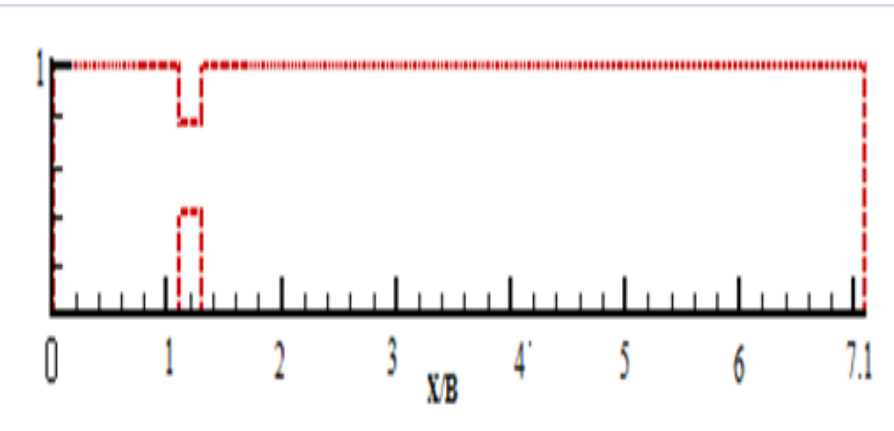

(a) 2-D channel with contraction/expansion

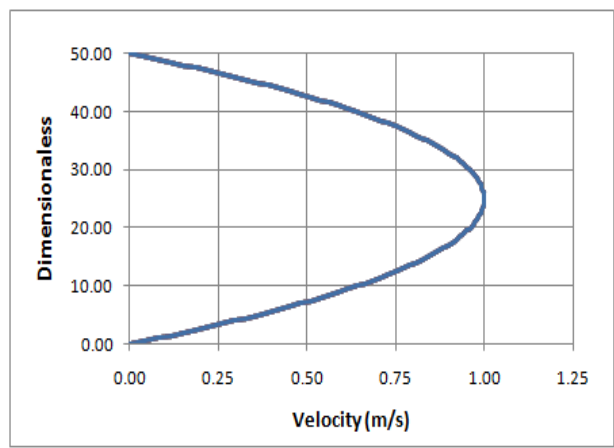

(b) Velocity profile as inlet boundary Fig. 8 Long channel plan and inlet velocity profile

The velocity values were computed using the developed model with Re value of 60; parabolic velocity profile was specified at the inlet boundary condition (Figure 8b). Figure 9(a) shows that velocity profile at location $\mathrm{X} / \mathrm{B}=1$ i.e. before contraction section in parabolic cross-section of channel which represents the model is simulating the motion fairly well. It has been observed that a shooting flow with high velocity was observed as shown in Figure 9 (b and c).

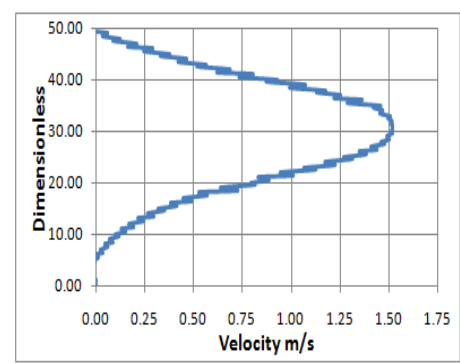

(a) Before contraction at $\mathrm{X} / \mathrm{B}=1$

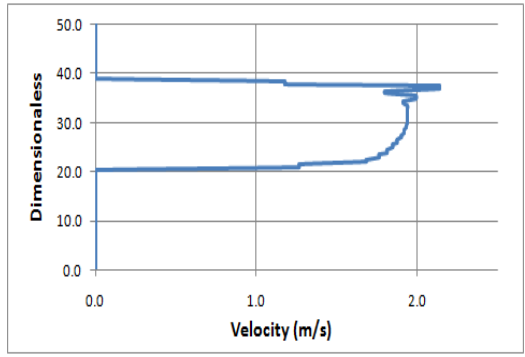

(b) At Contraction (i.e. $\mathrm{X} / \mathrm{B}=1.1$ )

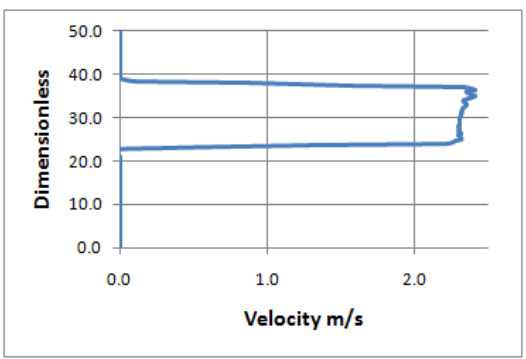

(c) During Contraction (i.e. $\mathrm{X} / \mathrm{B}=1.2$ ) Fig. 9 Velocity profile predicted before, at and during the contraction of the channel

The velocity profile computed for location $\mathrm{X} / \mathrm{B}=2$ shows fluctuation with maximum velocity of about $2.35 \mathrm{~m} / \mathrm{s}$ and negative velocity of $1.5 \mathrm{~m} / \mathrm{s}$ at the lower corner and some fluctuations of small positive and negative velocity at the upper corner (see Figure 10a). Figure 10(b) displays velocity profile at vertical section of $\mathrm{X} / \mathrm{B}=3$ i.e. about one-third of the expansion portion; negative velocity is $-1.0 \mathrm{~m} / \mathrm{s}$ and maximum velocity is $2.25 \mathrm{~m} / \mathrm{s}$.

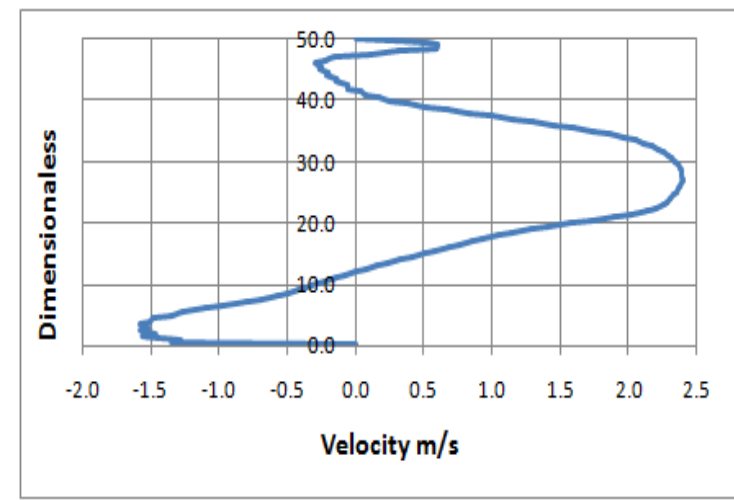

(a) At $\mathrm{X} / \mathrm{B}=2$

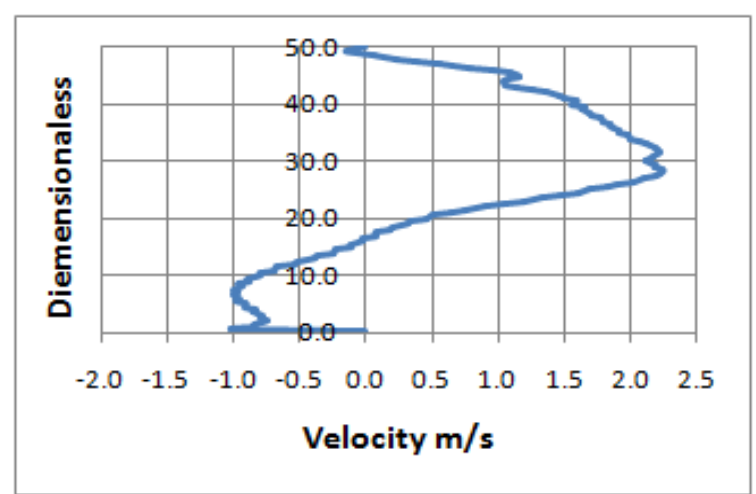

(b) At $\mathrm{X} / \mathrm{B}=3$

Fig. 10 Velocity profiles at downstream of the Channel

It was observed that velocity at point $(\mathrm{X} / \mathrm{B}=3)$ has been reducing at lower corner against the upper corner. The negative velocity at both locations was observed which has been shedding vortex at lower corners of the channel. The velocity profile at front of contraction portion (i.e. $\mathrm{X} / \mathrm{B}=2$ or $\mathrm{X}=100$ ) shows generating eddies and turbulent flow with maximum negative velocity of $1.6 \mathrm{~m} / \mathrm{s}$ which diminishing if compared with other figures in downstream (e.g. at $\mathrm{X} / \mathrm{B}=2$ velocity is $-1.5 \mathrm{~m} / \mathrm{s}$ ). 
The velocity profiles at location $\mathrm{X} / \mathrm{B}=5$ and 6 (i.e. $\mathrm{X}=250$ and $300 \mathrm{~m}$ respectively) are displayed in Figure 11 ( $a$ and $b$ ) which are in fluctuation, shows maximum velocity of 2.25 and $2.0 \mathrm{~m} / \mathrm{s} \mathrm{respectively.} \mathrm{While}$ comparing with Figure 10 ( $\mathrm{a}$ and $\mathrm{b}$ ), it is observed that the negative velocity is diminishing at $\mathrm{X} / \mathrm{B}=5$ and 6 , which is -0.7 and $-0.6 \mathrm{~m} / \mathrm{s}$ respectively.

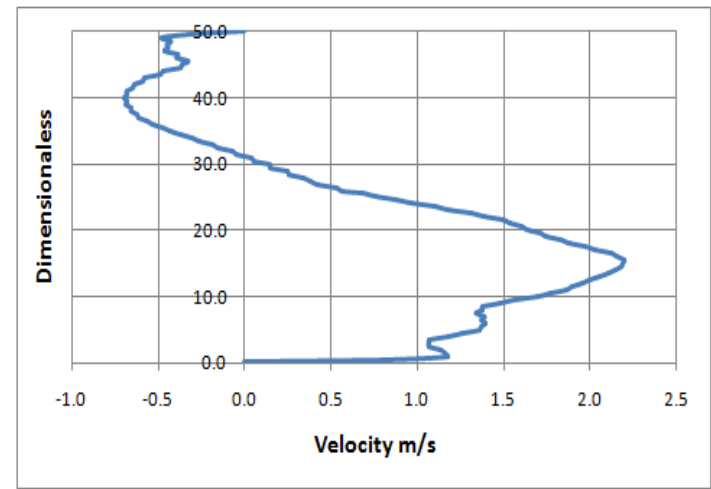

(a) At $\mathrm{X} / \mathrm{B}=5$

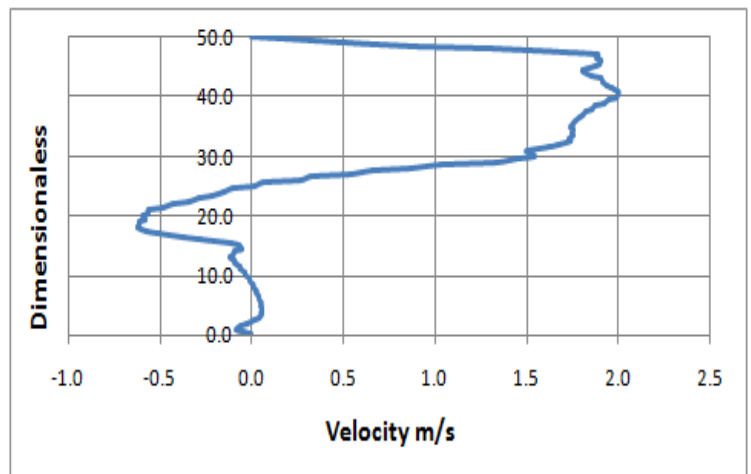

(b) At $\mathrm{X} / \mathrm{B}=6$

Fig. 11 Velocity profiles at tail of the channel

\section{Conclusion}

The developed model has been employed to predict velocity values at various distances in a twodimensional channel, which shows development of velocity profiles changes rapidly near the inlet and then gradually approaches to the analytical solution. The computed numerical results of the proposed model against analytical solution and numerical prediction of [2] exhibit a good agreement among them.

The present model was employed for computing streamline behaviour and flow condition in both short and long channels using $\mathrm{Re}=10$. In short channel, steady state solution was obtained at time units of 783.8 ; whereas unsteady condition was observed in long channel for same Re value at $\mathrm{T}=800$ and more. The variation of streamline behaviour and observation of steady/unsteady conditions exhibits due to difference of downstream lengths. The streamline contours have been developed using Tec-plot software.

The simulations were also made for high Reynolds number values up to 500 with various time units utilizing long channel to observe streamline behaviour in the channel. The vortices grow very large and project some considerable distance of the expansion plane, and then the longitudinal structure of entire eddy appears to increase non-linearly with increasing Reynolds number.

The velocity values computed using the model for Re of 60 employing a parabolic velocity profile at inlet, it was observed that a shooting flow with high velocity predicted in the contraction portion. The maximum positive velocity computed at location $\mathrm{X} / \mathrm{B}=2$ is $2.35 \mathrm{~m} / \mathrm{s}$ at just after the contraction/expansion, which is reduced to maximum of $2.0 \mathrm{~m} / \mathrm{s}$ at $\mathrm{X} / \mathrm{B}=6$. In the downstream portion, initially high negative velocity was observed i.e. more than $-1.5 \mathrm{~m} / \mathrm{s}$ at the lower corner of the channel, which is reduced to $-1.0 \mathrm{~m} / \mathrm{s}$ at X/B $=3$ (i.e. about one-third of the expansion portion) and further diminished to -0.7 and $-0.6 \mathrm{~m} / \mathrm{s}$ at locations $\mathrm{X} / \mathrm{B}=5$ and 6 respectively.

Consequently, it was obtained that the developed semi-implicit time-marching Taylor-Galerkin pressure-correction finite element model was found stable and accurate in the prediction of steady and unsteady flows in open channels.

\section{Acknowledgement}

The authors are grateful to the Institute of Water Resources Engineering and Management, Mehran University Engineering and Technology, Jamshoro, Pakistan, for providing facilities to conduct this research work.

\section{References}

[1] Cbapra Steven C. and Canale Raymond P., Numerical Methods for Engineers with Programming and Software Applications, McGraw-Hill International Editions, General Engineering Series, 1998.

[2] Y. Jia and Sam S. Y. Wang, CCHE2D Verification and Validation Tests Documentation, Technical Report No. NCCHE-TR-20012 .

[3] Baloch, A, Numerical Simulation of Complex Flows of Non-Newtonian Fluids, Ph.D. Thesis, University of Wales, Swansea, UK, 1994.

[4] S. K. W. Tou, A 2-D Finite Element Model for Unsteady Free-Surface Flow and its Experimental Verification, Computer-Aided Civil and Infrastructure Engineering, 6(4), pp. 335-342, 1991.

[5] J. J. Leendertse, A water quality simulation model for well-mixed estuaries and coastal seas, Principle of Computation, 1, the Rand Corporation RM-6230, 1970,. 
[6] R. A. Falconer, P. Goodwin and R.G.S. Matthew (Eds.), Hydraulic and Environmental Modelling of Coastal, Estuarine and River Water, Gower Technical, Aldershot, 1989.

[7] Vincenzo Casulli, Filippo Notamicola, An Eulerian -Lagrangian method for tidal current computation, Computer Modelling in Ocean Engineering (Schrefler \& Zienkiewocz, eds), Belkama, Rotterdam, pp.237-244, 1988.

[8] J. Mamizadeh and S.A. Ayyoubzadeh, Simulation of Flow Pattern in Open Channels with Sudden Expansions, Research Journal of Applied Sciences, Engineering and Technology, 4(19): pp.3852-3857, 2012.

[9] Johnson, C. "A New Paradigm for Adaptive Finite Element Methods, In The Mathematics of Finite Elements and Application, (Whiteman, J.R, Ed.) Johan Wiley and Sons, Inc., New York, 1994.

[10] Baloch A. and Qureshi A. L., "Parallel Simulation of Fluid Flow Past a Square Obstacle, Mehran University Research Journal of Engineering \& Technology, MUET, Jamshoro, Pakistan, 25(1), pp. 1-8, 2006.

[11] Durga C. Dalal and Swapan K. Pandit, Transient Solution of Incompressible Viscous Flow in a Channel with Sudden Expansion/Contraction, World academy of Science, Engineering and Technology (WASET), International Science Index, 6(7), pp. 136-147, 2012

[12] Donea, J., A Taylor-Galerkin Method for Convective Transport Problems, Int. J. Num. Meth. Eng, 20, pp.101-119, 1984

[13] Townsend, P. and Webster, M.F., An algorithm for three-dimensional transient simulation of non-Newtonian fluid flows, In: Theory and Applications, Proc. of Numeta Conf., Num. Meth., NUMETA 87, 2, T12/1-11, Nijhoff, 1987.

[14] Hawkin, D. M., Townsend, P. and Webster, M. F., A Finite Element Simulation of Viscous Flow Around a Cylinder, Report \# CSR 13-89, 1989

[15] Tamaddon-Jahromi,H. R., Ding, D., Webster, M.F. and Townsend, P., Taylor Galerkin Finite Element Method for Non-Newtonian Flows", Intl. J. Num Meth. Eng., 95, pp. 301-315, 1992

[16] Qureshi, A. L., and Baloch, A., Finite Element Simulation of Suspended Sediment Transport: Development, Validation of Application to Photo Minor, Sindh, Pakistan", (Fukuoka et al., ed.), Advances in River Sediment Research, Taylor and Francis Group, London, 2013.

[17] A. L. Qureshi, A. A. Mahessar and A. Baloch, Verification and Application of Finite Element Model developed for Flood Routing in Rivers, World Academy of Science, Engineering and Technology (WASET), International Journal of Environmental, Earth Science and Engineering, 8(2), pp. 24-27, 2014.

[18] Ali Asghar Mahessar, Ahsanullah Baloch and Abdul Latif Qureshi, Pseudo Three-Dimensional Finite Element Model for Unsteady Free Surface Flow, Jökull Journal (The Iceland Journal of Life Sciences), 64(4), pp. 426-436, 2014. 